\title{
Prostate cancer-specific death in brachytherapy treated high-risk patients stratified by pre-treatment PSA
}

\author{
Gregory S. Merrick, MD',2, Robert W. Galbreath, PhD',3, Wayne M. Butler, PHD', Ryan Fiano, MPH', \\ Edward Adamovich, MD4 \\ ISchiffler Cancer Center and Wheeling Jesuit University, Wheeling, WV, ${ }^{2}$ Wheeling Hospital, Department of Urology, Wheeling, WV. \\ ${ }^{3}$ Ohio University Eastern, St. Clairsville, OH, ${ }^{4}$ Wheeling Hospital, Department of Pathology, Wheeling, WV, USA
}

\begin{abstract}
Purpose: To evaluate prostate-cancer specific mortality (PCSM) in a cohort of high-risk patients treated with a permanent prostate brachytherapy approach, stratified by pre-treatment PSA.

Material and methods: 448 high-risk patients (NCCN criteria) underwent permanent prostate brachytherapy. High risk patients were stratified by pre-treatment PSA $(\leq 10.0,10.1-20$, and $>20 \mathrm{ng} / \mathrm{ml})$. Biochemical failure (BF), prostate cancer-specific mortality (PCSM), distant failure (DM), and overall mortality (OM) were assessed as a function of prognostic group. Multiple clinical, treatment, and dosimetric parameters were evaluated for impact on outcome.

Results: The 10-year OM, BF, and PCSM for the entire cohort were $28.5 \%, 13.3 \%$, and $4.9 \%$, respectively. At 10 years, PCSM was $2.5 \%, 10.7 \%$, and $4.5 \%$ in the PSA $\leq 10,10.1-20$, and $>20 \mathrm{ng} / \mathrm{ml}$ groups, respectively. No statistically significant differences in BF or overall survival (OS) were noted when stratified by pre-treatment PSA. DF was the most common in the $10.1-20 \mathrm{ng} / \mathrm{ml}$ cohort $(8.6 \%$ at 10 years). In multivariate analysis, PCSM was most closely related to percent positive biopsies $(p=0.001)$ and tobacco $(p=0.042)$.

Conclusions: High-risk prostate cancer treated with permanent prostate brachytherapy and supplemental external beam radiotherapy resulted in excellent long-term biochemical control and PCSM. Overall, PCSM was low in all cohorts but highest in the intermediate PSA group $(10.1-20 \mathrm{ng} / \mathrm{ml})$.

Key words: high-risk disease, prostate cancer, prostate cancer-specific death, PSA.

\section{Purpose}

The National Comprehensive Cancer Network (NCCN) defines high-risk prostate cancer according to the following criteria: clinical stage T3, Gleason score 8-10, and/or prostatic specific antigen (PSA) $>20 \mathrm{ng} / \mathrm{ml}$ [1]. Low-doserate (LDR) brachytherapy with supplemental external beam radiation therapy (EBRT) has been demonstrated to be a highly efficacious treatment for high-risk prostate cancer [2]. Recently, the ASCENDE-RT trial demonstrated marked improvement in biochemical disease-free survival when a brachytherapy boost was added to supplemental external beam radiation therapy compared to definitive intensity modulated external beam radiation therapy (IMRT) [3]. In addition, in multi-institutional studies, the results of dose-escalation using a brachytherapy boost in high-risk patients resulted in decreased prostate cancerspecific survival (PCSM) [4,5].

Mahal and colleagues using the Surveillance Epidemiology and End Results (SEER) database concluded that high-risk patients treated with either surgical or radiotherapeutic approaches presenting with either a very low
$(<2.5 \mathrm{ng} / \mathrm{ml})$ or very high $(>40 \mathrm{ng} / \mathrm{ml})$ PSA had a markedly increased risk of PCSM [6]. The authors concluded that increased PCSM in patients with a low pre-treatment PSA and Gleason scores of 8-10 was suggestive of the presence of very aggressive low producing PSA cancers. Previously, we reported high rates of biochemical control in high-risk patients treated with a brachytherapy approach [2]. In this study, we evaluate the impact of pre-treatment PSA on PCSM in patients with high-risk disease treated with high quality brachytherapy (a post-implant dose to the prostate gland $>100 \%$ of prescription dose, $\mathrm{D}_{90}$ ) with or without supplemental external beam radiation therapy (EBRT) and/or androgen deprivation therapy (ADT).

\section{Material and methods}

From April 1995 to January 2014, 448 patients with NCCN high-risk prostate cancer (clinical stage T3 or Gleason score 8-10, and/or PSA > $20 \mathrm{ng} / \mathrm{ml}$ ) underwent permanent prostate brachytherapy by a single brachytherapist. The high-risk patients were divided into 3 cohorts based on pre-treatment PSA $(\leq 10.0 \mathrm{ng} / \mathrm{ml}, n=248$; 10.1- 
$20.0 \mathrm{ng} / \mathrm{ml}, n=97 ;$ and $>20 \mathrm{ng} / \mathrm{ml}, n=103$ ). A secondary analysis was performed stratifying patients by PSA as per the SEER reported data [6]. The SEER data stratified patients into 5 categories: $<4 \mathrm{ng} / \mathrm{ml}, n=16 ; 4-10.0 \mathrm{ng} / \mathrm{ml}$, $n=232 ; 10.1-20 \mathrm{ng} / \mathrm{ml}, n=97 ; 20.1-40 \mathrm{ng} / \mathrm{ml}, n=85$; and $>40 \mathrm{ng} / \mathrm{ml}, n=18$. Because of small numbers in some of the cohorts, the primary evaluation consisted of the above mentioned 3 patient group stratification. All patients underwent brachytherapy more than 3 years prior to analysis. Prior to implantation, all slides underwent review by a pathologist with significant expertise in prostate pathology. Our pre-planning technique, intraoperative approach, and dosimetric evaluation have been described previously $[7,8]$. Patients were clinically staged using medical history and physical examination including digital rectal examination and serum PSA. Bone scans and computed tomography of the abdomen and pelvis were obtained in all patients. In all patients, prophylactic alpha-blockers were initiated two weeks prior to implantation and continued until the urinary symptoms were resolved.

The brachytherapy planning target volume consisted of prostate gland with a $5 \mathrm{~mm}$ periprostatic margin in the proximal $1.0 \mathrm{~cm}$ of the seminal vesicles $[7,8]$. All post-implant dosimetric calculations were based on day 0 dosimetric evaluation. Within 2 hours of implantation, a thin-slice $3 \mathrm{~mm}$ CT scan was obtained for evaluation of post-implant dosimetric coverage. Evaluated dosimetric parameters included the percentage of the target volume receiving $100 \%, 150 \%$, and $200 \%$ of the prescribed dose $\left(\mathrm{V}_{100 / 150 / 200}\right)$, and the minimum percentage of the dose covering $90 \%$ of the target volume $\left(D_{90}\right)$.

Four-hundred and forty-five of the 448 patients $(99.1 \%)$ received supplemental EBRT. In general, 45-50.4 Gy were delivered in 1.8 Gy fractions utilizing 15-18 MV photons delivered via either a 3-dimensional conformal or intensity modulated external beam radiation therapy technique. The target volume consisted of the prostate gland, seminal vesicles, and pelvic lymph nodes. The pelvic lymph nodes were treated superiorly to the L5-S1 interspace. The dose to $50 \%$ of the rectum (R50) was limited to $\leq 30 \mathrm{~Gy}$. In all cases, supplemental EBRT was delivered prior to brachytherapy.

Three-hundred and twenty-five of the 448 patients (72.4\%) received ADT. Two-hundred and seventy-three patients $(60.8 \%)$ received long-term (> 6 months) ADT, while 52 patients $(11.6 \%)$ received short-course ( $\leq 6$ months) of ADT. When prescribed, ADT was initiated 3 months prior to implantation and consisted of a luteinizing hormone-releasing hormone agonist, or antagonist with or without an anti-androgen. The median ADT duration was 4 and 24 months in the short course and extended course groups, respectively (range, 3-36 months).

Patients were monitored by physical examination including digital rectal examination and PSA measurement at 3-6 month intervals. The primary endpoint of the analysis was prostate cancer-specific mortality (PCSM). The cause of death was determined for each deceased patient. Patients with metastatic prostate cancer and/or non-metastatic castrate-resistant disease who died of any cause were classified as prostate cancer death. All other deaths were attributable to the immediate cause of death. In addition, biochemical failure $(\mathrm{BF})$ was analyzed. Biochemical failure was defined as a PSA $\leq 0.40 \mathrm{ng} / \mathrm{ml}$ after nadir. Patients who failed to achieve a PSA nadir $\leq 0.40 \mathrm{ng} / \mathrm{ml}$ were categorized as a BF. Multiple clinical, treatment, and dosimetric parameters were evaluated with further effect on outcome.

Patients were grouped based on pre-implant PSA. Clinical and treatment variables that were continuous were compared across groups using a one-way analysis of variance (ANOVA). Categorical variables were compared using a $\mathrm{X}^{2}$ analysis. All-cause mortality was compared across the grouping of PSA and across the 3 levels of risk using a cox-regression analysis. Biochemical failure and PCSM across the 3 or 5 PSA groups were determined using competing risk analysis. STATA version 12.0 software (StataCorp, College Station, TX, USA) and SPSS version 17.0 (Chicago, Il, USA) were used for all analysis with significance set at $p \leq 0.05$.

\section{Results}

Table 1 summarizes the clinical, treatment, and dosimetric parameters for the 448 patients stratified by pre-implant PSA ( $\leq 10 \mathrm{ng} / \mathrm{ml}, 10.1 \mathrm{ng} / \mathrm{ml}$, and $\geq 20.0 \mathrm{ng} / \mathrm{ml}$ ). The mean and median follow-up for entire group was 9.2 and 8.8 years, respectively. Compared to the other two cohorts, patients with a pre-treatment PSA > $20 \mathrm{ng} / \mathrm{ml}$ were statistically younger with longer follow-up, were less likely to present with Gleason 8-10 histology, were more likely to present with clinical $\geq \mathrm{T} 2 \mathrm{~b}$ stage, to receive long term (> 6 month) ADT, were more likely to present with poor high risk disease and lower pre-treatment testosterone levels. The median post-treatment PSA for all biochemically controlled patients was $<0.02 \mathrm{ng} / \mathrm{ml}$.

Figure 1 illustrates overall mortality (OM), biochemical failure (BF), and prostate cancer-specific mortality (PCSM) for the entire group at 10 and 15 years. At 10 years, $\mathrm{OM}, \mathrm{BF}$, and PCSM were $28.5 \%, 13.3 \%$, and $4.9 \%$, respectively. Figure 2 illustrates a competing risk analysis for biochemical failure stratified by pre-implant PSA with no statistically significant differences at 10 years $(11.9 \%$, $16.7 \%$, and $13.9 \%, p=0.339$ ). The mean and median time to BF in PSA cohorts < 10, 10-20, and $>20$ were 3.35 years and 3.22 years, 2.65 years and 2.56 years, and 1.84 years and 1.69 years, respectively. Figure 3 illustrates OS at 10 and 15 years stratified by the 3 PSA cohorts without statistically significant differences in $\operatorname{survival}(p=0.310)$. When PCSM was stratified by the 3 pre-implant PSA cohorts (Table 2), statistically significant differences were discerned at 10 years (Figure 4). The 10-year PCSM for pre-treatment PSA $\leq 10,10.1-20$, and $>20$ were $2.5 \%, 10.7 \%$, and $4.5 \%$, respectively $(p=0.0156)$. When patients were stratified into the 5 SEER cohorts, the number of patients in some of the individual groups were very small. No statistical difference in OM $(p=0.333)$ or BF $(0.603)$ was discernible. PCSM and distant failure (DF) were substantially greater in patients with a pre-treatment PSA of $10.1-20.0 \mathrm{ng} / \mathrm{ml}$ compared to the other 4 cohorts $(p<0.001)$ for both PCSM and DF. 
Table 1. High-risk patients stratified by pre-implant prostate-specific antigen (PSA)

\begin{tabular}{|c|c|c|c|c|c|c|c|c|c|}
\hline \multirow{2}{*}{ Continuous variables } & \multicolumn{2}{|c|}{$\leq 10.0(n=232)$} & \multicolumn{2}{|c|}{$10.1-20(n=97)$} & \multicolumn{2}{|c|}{$>20(n=85)$} & \multirow[t]{2}{*}{$p$} & \multicolumn{2}{|c|}{ Total $(n=448)$} \\
\hline & Mean & Median & Mean & Median & Mean & Median & & Mean & Median \\
\hline Age at implant & 66.9 & 67.5 & 67.1 & 68 & 64.3 & 64 & 0.005 & 66.3 & 67 \\
\hline Follow-up (years) & 8.7 & 8.0 & 9.2 & 8.9 & 10.3 & 10.1 & 0.010 & 9.2 & 8.8 \\
\hline Gleason score & 8.4 & 8.0 & 8.5 & 8.0 & 7.4 & 7 & $<0.001$ & 8.2 & 8.0 \\
\hline Percent positive biopsies & 48.7 & 43.7 & 58.5 & 53.6 & 57.2 & 58.3 & 0.003 & 52.8 & 50 \\
\hline BMI & 29.2 & 28.3 & 29.3 & 28.4 & 28.8 & 27.8 & 0.770 & 29.1 & 28.3 \\
\hline$D_{90 \%}$ & 122.3 & 123.3 & 120.4 & 120.5 & 120.8 & 120.8 & 0.317 & 121.5 & 122.1 \\
\hline$V_{100}$ & 97.5 & 98.5 & 96.7 & 98.1 & 96.9 & 97.9 & 0.071 & 97.2 & 98.3 \\
\hline$V_{150}$ & 71.6 & 73.9 & 70.7 & 72.8 & 69.2 & 73.2 & 0.097 & 71.0 & 73.5 \\
\hline$V_{200}$ & 42.9 & 43.5 & 42.6 & 43.9 & 40.7 & 44.4 & 0.188 & 42.3 & 43.8 \\
\hline Last PSA & 0.01 & $<0.02$ & 0.01 & $<0.02$ & 0.01 & $<0.02$ & $<0.001$ & 0.01 & $<0.02$ \\
\hline Categorical variables & Mean & Median & Mean & Median & Mean & Median & $p$ & Mean & Median \\
\hline \multicolumn{10}{|l|}{ Gleason score } \\
\hline 6 & 0 & $(0.0)$ & 1 & (1.0) & 18 & $(17.5)$ & \multirow[t]{5}{*}{$<0.001$} & 19 & $(4.2)$ \\
\hline $7(3+4)$ & 1 & $(0.4)$ & 0 & $(0.0)$ & 13 & (12.6) & & 14 & (3.1) \\
\hline $7(4+3)$ & 1 & $(0.4)$ & 1 & (1.0) & 30 & (29.1) & & 32 & (7.1) \\
\hline 8 & 151 & $(60.9)$ & 49 & $(50.5)$ & 20 & (19.4) & & 220 & $(49.1)$ \\
\hline 9 & 95 & $(38.3)$ & 46 & $(47.4)$ & 22 & (21.4) & & 163 & $(36.4)$ \\
\hline \multicolumn{10}{|l|}{ Stage } \\
\hline$\leq \mathrm{T} 2 \mathrm{a}$ & 187 & $(75.4)$ & 69 & $(71.1)$ & 61 & $(59.2)$ & \multirow[t]{2}{*}{0.010} & 317 & (70.8) \\
\hline$\geq \mathrm{T} 2 \mathrm{~b}$ & 61 & $(24.6)$ & 28 & (28.9) & 42 & $(40.8)$ & & 131 & $(29.2)$ \\
\hline \multicolumn{10}{|l|}{ Isotope } \\
\hline${ }^{103} \mathrm{Pd}$ & 247 & (99.6) & 97 & (100) & 92 & (89.3) & \multirow[t]{2}{*}{$<0.001$} & 436 & \multirow{2}{*}{$\begin{array}{c}(2.7) \\
(97.3)\end{array}$} \\
\hline 125 & 1 & $(0.4)$ & 0 & $(0.0)$ & 11 & $(10.7)$ & & 12 & \\
\hline \multicolumn{10}{|l|}{ XRT } \\
\hline No & 2 & (0.8) & 2 & (2.1) & 0 & $(0.0)$ & \multirow[t]{2}{*}{0.640} & 4 & $(0.9)$ \\
\hline Yes & 246 & (99.2) & 95 & $(97.9)$ & 103 & (100) & & 445 & (99.1) \\
\hline \multicolumn{10}{|l|}{ ADT } \\
\hline None & 96 & (38.7) & 14 & (14.4) & 13 & (12.6) & \multirow[t]{3}{*}{$<0.001$} & 123 & $(27.6)$ \\
\hline$\leq 6$ months & 40 & (16.1) & 6 & $(6.2)$ & 6 & (5.8) & & 52 & (11.6) \\
\hline$>6$ months & 112 & $(45.2)$ & 77 & (79.4) & 84 & (81.6) & & 273 & (60.8) \\
\hline \multicolumn{10}{|l|}{ Testosterone } \\
\hline$\leq 1 / 3$ normal & 130 & (73.0) & 50 & (71.4) & 33 & $(53.2)$ & \multirow[t]{3}{*}{0.001} & 214 & (68.8) \\
\hline Mid 1/3 normal & 35 & (19.7) & 17 & $(24.3)$ & 22 & $(35.5)$ & & 74 & (23.8) \\
\hline$\geq 1 / 3$ normal & 13 & (7.3) & 3 & (4.3) & 7 & (11.3) & & 23 & $(7.4)$ \\
\hline \multicolumn{10}{|l|}{ Hypertension: } \\
\hline No & 101 & (70.7) & 46 & $(47.4)$ & 49 & $(47.6)$ & \multirow[t]{2}{*}{0.433} & 196 & $(43.7)$ \\
\hline Yes & 147 & (59.3) & 51 & $(52.6)$ & 54 & (52.4) & & 252 & (56.3) \\
\hline
\end{tabular}


Table 1. Cont.

\begin{tabular}{|c|c|c|c|c|c|c|c|c|c|}
\hline \multirow[b]{2}{*}{ Categorical variables } & \multicolumn{2}{|c|}{$\leq 10.0(n=232)$} & \multicolumn{2}{|c|}{$10.1-20(n=97)$} & \multicolumn{2}{|c|}{$>20(n=85)$} & \multirow[t]{2}{*}{$p$} & \multicolumn{2}{|c|}{ Total $(n=448)$} \\
\hline & Mean & Median & Mean & Median & Mean & Median & & Mean & Median \\
\hline \multicolumn{10}{|l|}{ Diabetes } \\
\hline No & 205 & $(82.7)$ & 85 & $(87.6)$ & 95 & $(92.2)$ & \multirow[t]{2}{*}{0.117} & 385 & (85.9) \\
\hline Yes & 43 & $(17.3)$ & 12 & $(12.4)$ & 8 & $(7.77)$ & & 63 & $(14.1)$ \\
\hline \multicolumn{10}{|l|}{ Hypercholesterolemia } \\
\hline No & 155 & $(62.5)$ & 59 & $(60.8)$ & 75 & $(72.8)$ & \multirow[t]{2}{*}{0.128} & 289 & $(64.5)$ \\
\hline Yes & 93 & $(37.5)$ & 38 & $(39.2)$ & 28 & $(27.2)$ & & 159 & $(35.5)$ \\
\hline \multicolumn{10}{|l|}{ Cardiovascular disease } \\
\hline No & 195 & (78.6) & 73 & $(75.3)$ & 83 & $(80.6)$ & \multirow[t]{2}{*}{0.650} & 351 & $(78.4)$ \\
\hline Yes & 53 & $(21.4)$ & 24 & $(24.7)$ & 20 & (19.4) & & 97 & $(21.6)$ \\
\hline \multicolumn{10}{|l|}{ Tobacco" } \\
\hline Never & 85 & $(34.7)$ & 38 & (39.6) & 32 & (31.4) & \multirow[t]{3}{*}{0.360} & 155 & (35.0) \\
\hline Former & 125 & $(51.0)$ & 41 & $(42.7)$ & 48 & $(47.0)$ & & 214 & $(48.3)$ \\
\hline Current & 35 & $(14.3)$ & 17 & $(17.7)$ & 22 & $(21.6)$ & & 74 & $(16.7)$ \\
\hline \multicolumn{10}{|l|}{ Perineural invasion } \\
\hline No & 128 & $(51.6)$ & 35 & (36.1) & 49 & $(47.6)$ & \multirow[t]{2}{*}{0.034} & 212 & $(47.3)$ \\
\hline Yes & 120 & $(48.4)$ & 62 & (63.9) & 54 & $(52.4)$ & & 236 & $(52.7)$ \\
\hline \multicolumn{10}{|l|}{ High-risk } \\
\hline Good & 243 & (98.0) & 92 & (94.9) & 60 & $(58.3)$ & \multirow[t]{3}{*}{$<0.001$} & 395 & $(88.2)$ \\
\hline Intermediate & 0 & $(0.0)$ & 0 & $(0.0)$ & 1 & (1.0) & & 1 & $(0.2)$ \\
\hline Poor & 5 & (2.0) & 5 & (5.2) & 42 & $(40.7)$ & & 52 & $(11.6)$ \\
\hline
\end{tabular}

$B M I-B o d y$ mass index, $D_{90 \%}$ - percent of the prescription dose covering $90 \%$ of the clinical target volume, $V_{100}, V_{150}, V_{200}-$ volumes of the anatomic volume receiving 100\%, 150\%, 200\% of the prescribed dose, PSA - prostate specific antigen, XTR - external beam radiotherapy, ADT - androgen deprivation therapy \# - only 311 patients had testosterone values and 5 patients did not have tobacco data

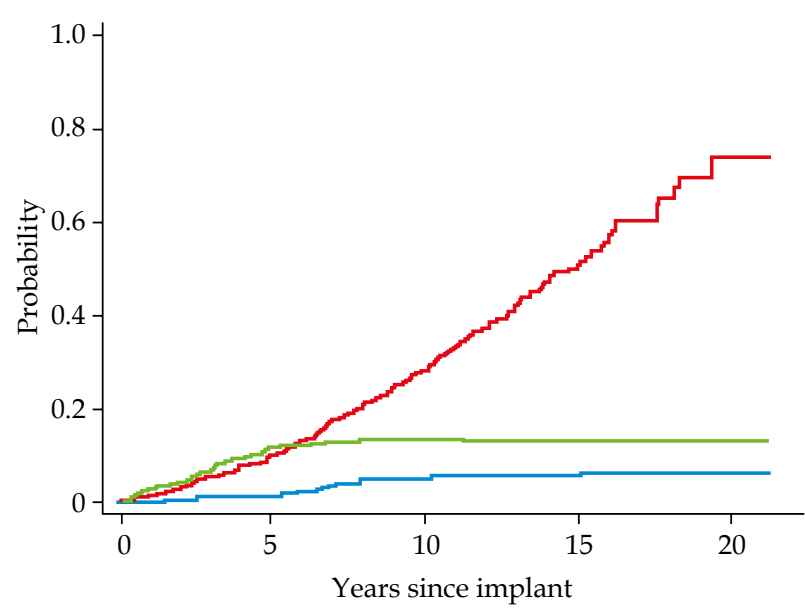

— Overall mortality, $0.285,0.515$

— Biochemical failure, 0.133, 0.133

— Prostate cancer-specific mortality, 0.049, 0.053

Fig. 1. Overall mortality (one-minus survival), biochemical failure (cumulative incidence), and prostate-specific failure (cumulative incidence) at 10 and 15 years

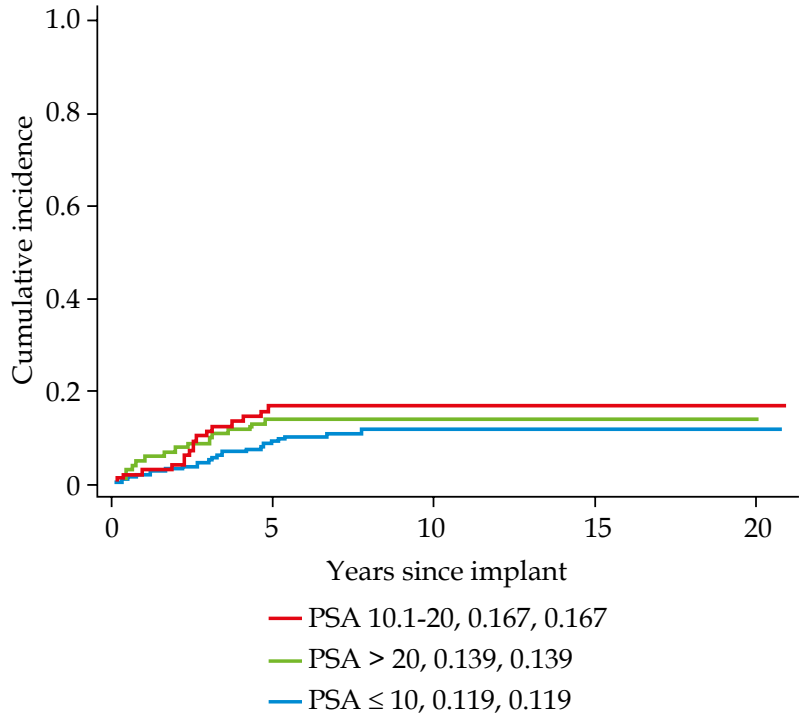

Fig. 2. Competing risks analysis for biochemical failure, stratified by pre-implant prostate-specific antigen (PSA) with probability provided at 10 and 15 years 


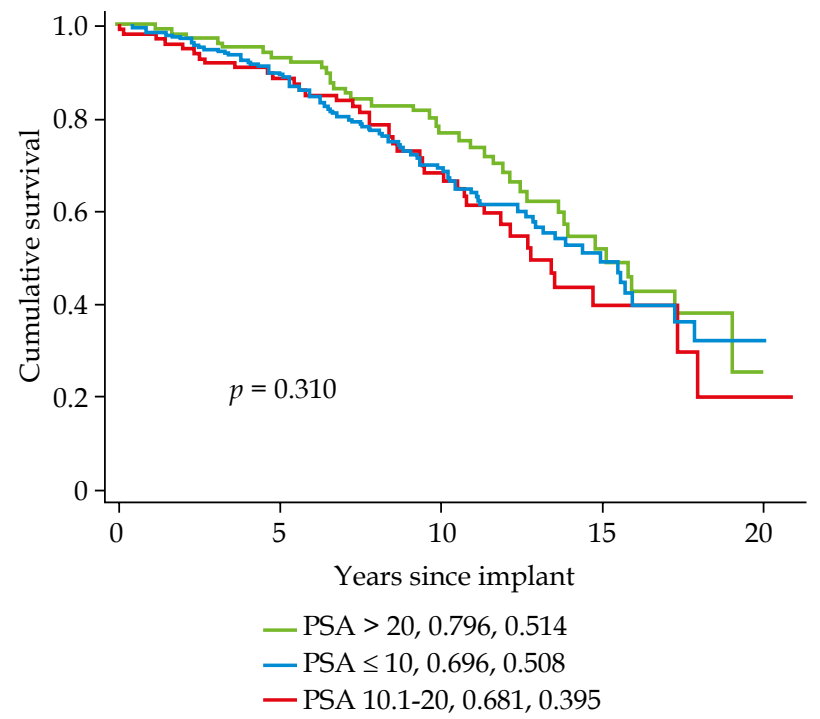

Fig. 3. Overall survival (Kaplan-Meier) stratified by pre-implant prostate-specific antigen (PSA) with probability provided at 10 and 15 years

Table 3 summarizes the multivariate analysis for $\mathrm{OM}, \mathrm{BF}$, and PCSM. In multivariate analysis, OM was best predicted by patient age $(p=0.001)$, percent positive biopsies $(p=0.005)$, Gleason score $(p=0.039)$, and low/ low normal testosterone $(p=0.005)$. For BF, percent positive biopsies $(p=<0.001)$ best predicted for outcome. For PCSM, percent positive biopsies $(p=0.001)$ and tobacco $(p=0.042)$ were the strongest predictors.

\section{Discussion}

Mahal and colleagues using the SEER data, which included radical prostatectomy and radiotherapy, treated patients with a median follow-up of 38 months, and demonstrated that PCSM was highest in patients with a pre-treatment PSA $<4.0 \mathrm{ng} / \mathrm{ml}$ or $>40.0 \mathrm{ng} / \mathrm{ml}$ [6]. The authors concluded that patients with very low PSA values have a prognosis similar to those with very high PSA levels. In our much smaller series but with substantially longer follow-up (mean and median follow-up 9.2 and 8.8 years), our brachytherapy results do not confirm the SEER data. In our series, PCSM was substantially low-

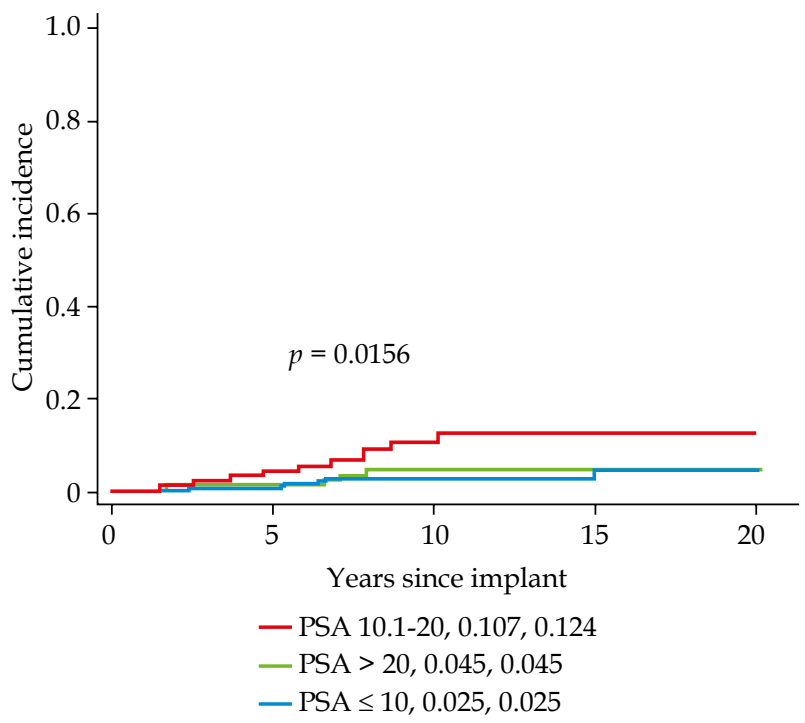

Fig. 4. Competing risks analysis for prostate cancer-specific mortality stratified by pre-implant prostate-specific antigen (PSA) with probability provided at 10 and 15 years

er for all PSA cohorts compared to the SEER data with the greatest risk of PCSM in patients with a pre-treatment PSA of $10.1-20 \mathrm{ng} / \mathrm{ml}$. Consistent with our results, a radical prostatectomy (RP) series did not demonstrate any difference in failure between patients with a very low pre-treatment PSA compared to those with higher pre-treatment PSA [9]. In contrast, a RP series of patients with Gleason scores 8-10 revealed non-statistical trends toward biochemical failure and increased distant metastasis in patients with pre-treatment PSA $\leq 2.5$ vs. $4.1-10 \mathrm{ng} / \mathrm{ml}$ [10].

$\mathrm{D}^{\prime}$ Amico et al. reported that patients with high-grade disease and a pre-treatment PSA $\leq 4 \mathrm{ng} / \mathrm{ml}$ had a shorter time to biochemical recurrence than patients with a PSA of $4.1-10.0 \mathrm{ng} / \mathrm{ml}$ [11]. In our series, we did not demonstrate any substantial differences in failure when stratified by PSA < 4 vs. $4-10$, but did note somewhat shorter times to failure in patients with a PSA $>20 \mathrm{ng} / \mathrm{ml}$ (median time to failure 1.69 years vs. patients with a pre-treatment PSA $\leq 10 \mathrm{ng} / \mathrm{ml}, 3.22$ years).

Local control has been demonstrated to improve PCSM in high-risk patients. The addition of EBRT to ADT has improved biochemical control, PCSM, and overall

Table 2. Ten- and 15-year mortality or failure (overall mortality, biochemical failure, prostate cancer-specific mortality, and distant failure) stratified by pre-treatment prostate-specific antigen (PSA)

\begin{tabular}{|c|c|c|c|c|c|c|c|c|c|c|c|}
\hline \multirow[t]{2}{*}{ Failure type } & \multicolumn{2}{|c|}{$<4.0(n=16)$} & \multicolumn{2}{|c|}{$4.0-10.0(n=232)$} & \multicolumn{2}{|c|}{$10.1-20.0(n=97)$} & \multicolumn{2}{|c|}{$20.1-40.0(n=85)$} & \multicolumn{2}{|c|}{$>40.0(n=18)$} & \multirow[t]{2}{*}{$p$} \\
\hline & $10 \mathrm{yr}$ & $15 \mathrm{yr}$ & $10 \mathrm{yr}$ & $15 \mathrm{yr}$ & $10 \mathrm{yr}$ & $15 \mathrm{yr}$ & $10 \mathrm{yr}$ & $15 \mathrm{yr}$ & $10 \mathrm{yr}$ & $15 \mathrm{yr}$ & \\
\hline Overall mortality ${ }^{1}$ & 0.219 & 0.219 & 0.309 & 0.507 & 0.319 & 0.604 & 0.229 & 0.479 & 0.128 & 0.477 & 0.333 \\
\hline Biochemical failure 2 & 0.103 & 0.103 & 0.120 & 0.120 & 0.168 & 0.168 & 0.132 & 0.132 & 0.167 & 0.167 & 0.603 \\
\hline $\begin{array}{l}\text { Prostate cancer- } \\
\text { specific mortality }^{2}\end{array}$ & 0.000 & 0.000 & 0.026 & 0.026 & 0.107 & 0.124 & 0.040 & 0.040 & 0.056 & 0.056 & $<0.001$ \\
\hline Distant failure ${ }^{2}$ & 0.000 & 0.000 & 0.022 & 0.022 & 0.086 & 0.086 & 0.012 & 0.012 & 0.056 & 0.056 & $<0.001$ \\
\hline
\end{tabular}


Table 3. Univariate and multivariate analysis for predicting biochemical failure, overall mortality, and prostate cancer-specific mortality

\begin{tabular}{|c|c|c|c|c|c|c|c|c|c|c|c|c|}
\hline \multirow[b]{3}{*}{ Continuous variables } & \multicolumn{4}{|c|}{ Overall mortality } & \multicolumn{4}{|c|}{ Biochemical failure } & \multicolumn{4}{|c|}{ Prostate cancer-specific mortality } \\
\hline & \multicolumn{2}{|c|}{ Univariate } & \multicolumn{2}{|c|}{ Multivariate } & \multicolumn{2}{|c|}{ Univariate } & \multicolumn{2}{|c|}{ Multivariate } & \multicolumn{2}{|c|}{ Univariate } & \multicolumn{2}{|c|}{ Multivariate } \\
\hline & $p$ & $\mathrm{HR}$ & $p$ & $\mathrm{HR}$ & $p$ & SHR & $p$ & $\mathrm{HR}$ & $p$ & SHR & $p$ & $\mathrm{HR}$ \\
\hline PSA & 0.113 & & & & 0.145 & & & & 0.512 & & & \\
\hline Age & $<0.001$ & 1.055 & 0.001 & 1.055 & 0.060 & & 0.301 & & 0.046 & & 0.209 & \\
\hline Percent positive biopsies & 0.002 & 1.009 & 0.002 & 1.013 & $<0.001$ & 1.019 & $<0.001$ & 1.018 & $<0.001$ & 1.030 & 0.001 & 1.028 \\
\hline BMI & 0.435 & & & & 0.150 & & & & 0.780 & & & \\
\hline$D_{90 \%}$ & 0.792 & & & & 0.668 & & & & 0.836 & & & \\
\hline \multicolumn{13}{|l|}{ Categorical variables } \\
\hline Perineural invasion & 0.148 & & & & 0.097 & & 0.789 & & 0.220 & & & \\
\hline Hypercholesterolemia & 0.362 & & & & 0.150 & & & & 0.241 & & & \\
\hline Cardiovascular disease & 0.142 & & & & 0.085 & & 0.223 & & $<0.001$ & * & & \\
\hline Diabetes & 0.604 & & & & 0.137 & & & & 0.617 & & & \\
\hline Hypertension & 0.972 & & & & 0.056 & & 0.116 & & 0.026 & 0.333 & 0.052 & \\
\hline Tobacco & 0.150 & & & & 0.615 & & & & 0.053 & & & \\
\hline Never vs. former & - & & & & - & & & & - & & 0.042 & 0.303 \\
\hline Never vs. current & - & & & & - & & & & - & & 0.533 & \\
\hline Gleason score & 0.139 & & & & $<0.001$ & & & & $x$ & & & \\
\hline 6 vs. $7(3+4)$ & & & & & $<0.001$ & $>100$ & $* * *$ & & & & & \\
\hline 6 vs. $7(4+3)$ & & & & & $<0.001$ & $>100$ & $* * *$ & & & & & \\
\hline 6 vs. 8 & & & & & $<0.001$ & $>100$ & $* * *$ & & & & & \\
\hline 6 vs. 9 & & & & & $<0.001$ & $>100$ & $* * *$ & & & & & \\
\hline ADT & 0.924 & & & & 0.264 & & & & 0.204 & & & \\
\hline ADT duration: & 0.587 & & & & 0.341 & & & & 0.4435 & & & \\
\hline $0 \mathrm{vs} . \leq 6$ months & - & & & & - & & & & - & & & \\
\hline 0 vs. $>6$ months & - & & & & - & & & & - & & & \\
\hline Pre-treatment PSA & 0.221 & & & & 0.597 & & & & $<0.001$ & $\star \star$ & & \\
\hline$<4.0$ & - & & & & - & & & & - & & & \\
\hline $4.1-10$ & - & & & & - & & & & - & & & \\
\hline $10.1-20$ & - & & & & - & & & & - & & & \\
\hline $20.1-40$ & - & & & & - & & & & - & & & \\
\hline$>40.0$ & - & & & & - & & & & - & & & \\
\hline Testosterone & 0.021 & & 0.016 & & 0.350 & & & & $<0.001$ & & & \\
\hline $\begin{array}{l}\text { Low \& low norm vs. } \\
\text { mid norm }\end{array}$ & 0.006 & 0.406 & 0.004 & 0.389 & - & & & & 0.480 & - & & \\
\hline $\begin{array}{l}\text { Low \& low norm vs. } \\
\text { high \& high norm }\end{array}$ & 0.539 & & 0.786 & & - & & & & $<0.001$ & * & & \\
\hline
\end{tabular}

PSA - prostate specific antigen, BMI - Body mass index, $D_{90 \%}$ - percent of the prescription dose covering $90 \%$ of the clinical target volume, ADT - androgen deprivation therapy

${ }^{*}$ Approaching negative infinity, so these variables were not included in further analyses

${ }^{* *}$ Approaching positive infinity, so this variable was not included in further analyses. Also there was only one failure in the PSA $\leq 4.0$ and $>40$ groups

${ }^{* * *}$ All sub-hazard ratios (SHR) were greater than $1 \times 10^{7}$ when each Gleason score was compared to a Gleason score of 6. So, Gleason score was not entered into multivariate analysis

${ }^{x}$ There were no prostate specific deaths in the comparison group (Gleason score 6) 
survival in patients with locally advanced prostate cancer $[12,13]$. Furthermore, 3 prospective randomized trials evaluating RP with or without adjuvant EBRT for prostate cancer with high-risk features demonstrated a $50 \%$ relative reduction in biochemical failure rates $[14,15,16]$. One study demonstrated a $9 \%$ statistically significant improvement in 10-year overall survival [14]. It is conceivable that the improved biochemical control rates and decreased PCSM in our cohort is due to high-quality prostate brachytherapy (day $0 \mathrm{D}_{90}$ of $121.5 \%$ of prescription) with generous periprostatic treatment margins with the inclusion of supplemental nodal EBRT and ADT. In the SEER data, brachytherapy dosimetric quality, EBRT radiation doses, and RP pathologic assessment are not accessible, and may have artificially influenced their conclusions [6].

In the current study, patients with a pre-treatment PSA $10.1-20 \mathrm{ng} / \mathrm{ml}$ had a greater incidence of PCSM (Figure $4, p=0.0156$ ) and DF (Table $2, p<0.001$ ). The poorer outcome in patients with an intermediate pre-treatment PSA is most likely result in a greater incidence of Gleason score 9 patients in that cohort (Table 1). Consistent with other studies (Table 3), tobacco consumption was related to an increased risk of prostate cancer death [17]. In addition, low pre-treatment testosterone levels were associated with decreased OS, which is consistent with one of our previous publications [18].

Shortcomings of our study include a relatively small number of patients treated at a single institution by a single brachytherapist. In addition, all retrospective evaluations were with inherent treatment bias. ADT was administered based on assessment of the treating physician without protocol guidelines, and as such its role in the management of these patients cannot be determined. Strengths of the study include that all patients were treated with a consistent brachytherapy and EBRT techniques with documented high-quality post-implant dosimetry.

\section{Conclusions}

High-risk prostate cancer treated with permanent prostate brachytherapy and supplemental EBRT results in excellent long-term biochemical control and PCSM. Overall, PCSM was low in all cohorts but highest in the intermediate PSA group (10.1-20 ng/ml).

\section{Disclosure}

Authors report no conflict of interest.

\section{References}

1. http://www.nccn.org/professionals/physician_gls/pdf/ prostate.pdf. Site accessed on 2/26/2015

2. Bittner N, Merrick GS, Galbreath RW et al. Treatment outcomes with permanent brachytherapy in high-risk prostate cancer patients stratified into prognostic categories. Brachytherapy 2015; 14: 766-772.

3. Morris WJ, Tyldesley S, Rodda S et al. Androgen suppression combined with elective nodal and dose escalated radiation therapy (the ASCENDE-RT trial): An analysis of survival endpoints for a randomized trial comparing a low-dose-rate brachytherapy boost to a dose-escalated external beam boost for high- and intermediate-risk prostate cancer. Int I Rad Oncol Biol Phys 2017; 98: 275-285.

4. Skilkrut M, Merrick GS, McLaughlin PW et al. The addition of low-dose-rate brachytherapy and androgen deprivation therapy decreases biochemical failure and prostate cancer death compared with dose-escalated external beam radiation therapy for high-risk prostate cancer. Cancer 2013; 119: 681-690.

5. Kishan AU, Ciezki JP, Ross AE et al. Extremely dose escalated radiotherapy improves cancer-specific survival compared with radical prostatectomy or conventionally dose-escalated radiotherapy in Gleason score 9-10 prostate adenocarcinoma: A multi-institutional analysis of 1403 patients. $58^{\text {th }}$ Annual meeting of the American Society for Radiation Oncology. San Diego, CA. September 24-27, 2017. Oral presentation.

6. Mahal BA, Aizer AA, Efstathiou JA et al. Association of very low prostate-specific antigen levels with increased cancer-specific death in men with high-grade prostate cancer. Cancer 2016; 122: 78-83.

7. Merrick GS, Butler WM. Modified uniform seed loading for prostate brachytherapy: rationale, design and evaluation. Tech Urol 2000; 6: 78-84.

8. Merrick GS, Butler WM, Wallner KE et al. Dosimetry of an extracapsular annulus following permanent prostate brachytherapy. Am J Clin Oncol 2007; 30: 228-233.

9. Berglund RK, Stephenson AJ, Cronin AM et al. Comparison of observed biochemical recurrence-free survival in patients with low PSA values undergoing radical prostatectomy and predictions of pre-operative nomogram. Urology 2009; 73: 1098-1103.

10. McGuire BB, Helfand BT, Loeb S et al. Outcomes in patients with Gleason score 8-10 prostate cancer: relation to preoperative PSA level. BJU Int 2012; 109: 1764-1769.

11. D'Amico AV, Chen MH, Malkowicz SB et al. Lower prostate specific antigen outcome than expected following radical prostatectomy level of $4 \mathrm{ng} / \mathrm{ml}$ or less. J Urol 2002; 167: 20252030.

12. Widmark A, Klepp O, Solberg A et al. Endocrine treatment, with or without radiotherapy, in locally advanced prostate cancer (SPCG-7/SFUO-3): an open randomised phase III trial. Lancet 2009; 373: 301-308.

13. Warde $P$, Mason M, Ding K et al. Combined androgen deprivation therapy and radiation therapy for locally advanced prostate cancer: a randomized, phase 3 trial. Lancet 2011; 378: 2104-2111.

14. Thompson IM, Tangen CM, Paradelo J et al. Adjuvant radiotherapy for pathological T3N0M0 prostate cancer significantly reduces risk of metastases and improves survival: longterm follow up of a randomized clinical trial. J Urol 2009; 181: 956-962.

15. Bolla M, van Poppel H, Collette L et al. Postoperative radiotherapy after radical prostatectomy: a randomised controlled trial (EORTC trial 22911). Lancet 2005; 366: 572-578.

16. Wiegel T, Bottke D, Steiner U et al. Phase III postoperative adjuvant radiotherapy after radical prostatectomy compared with radical prostatectomy alone in $\mathrm{pT} 3$ prostate cancer with postoperative undetectable prostate-specific antigen: ARO 96-02/AUO AP 09/95. J Clin Oncol 2009; 27: 2924-2930.

17. Islami F, Moreira DM, Boffetta P et al. A systematic review and meta-analysis of tobacco use and prostate cancer mortality and incidence in prospective cohort studies. Eur Urol 2014; 66: 1054-1064.

18. Taira AV, Merrick GS, Galbreath RW et al. Impact of Androgen Deprivation Therapy on overall mortality in prostate brachytherapy patients with low pretreatment testosterone levels. Am J Clin Oncol 2016 [Epub ahead of print]. 